\title{
Rural Tourism in the South of Spain: An Opportunity for Rural Development
}

\author{
Genoveva Millán Vázquez de la Torre ${ }^{1}$, Luis Amador Hidalgo ${ }^{2}$, Juan Manuel Arjona Fuentes ${ }^{1}$ \\ ${ }^{1}$ Departament of Quantitative Methods, Universidad Loyola Andalucía, Córdoba, Spain \\ ${ }^{2}$ Departament of Economics, Universidad Loyola Andalucía, Córdoba, Spain \\ Email: gmillan@uloyola.es, lamador@uloyola.es, jmarjona@uloyola.es
}

Received December 24, 2013; revised January 24, 2014; accepted January 31, 2014

Copyright (c) 2014 Genoveva Millán Vázquez de la Torre et al. This is an open access article distributed under the Creative Commons Attribution License, which permits unrestricted use, distribution, and reproduction in any medium, provided the original work is properly cited. In accordance of the Creative Commons Attribution License all Copyrights (C) 2014 are reserved for SCIRP and the owner of the intellectual property Genoveva Millán Vázquez de la Torre et al. All Copyright (C) 2014 are guarded by law and by SCIRP as a guardian.

\section{ABSTRACT}

Tourism is one of the most enriching experiences, and even more so if it involves a rural habitat, in contact with the environment. This kind of tourism, one of the most requested by society currently, offers a great chance for developing rural areas. Rural tourism has become the solution for some problems that have become evident in those areas: the high rate of unemployment, rural exodus and primary sector dependence. So the practice of this activity will generate and diversify income, and create employment. For this reason it is necessary to offer a product adapted to consumer tourist demand, and therefore it is essential to know profile of the tourist. The Andalusian region, in the south of Spain, is famous for being a tourist area of great singularity exhibiting different degrees of development and models of touristic exploitation, strongly characterized by its offer of sun and beach. Today, this community does not limit itself to offering only a sun and beach experience since not all tourists that choose it as their destination have exclusive preference for this sector. Among all the new proposals, one modality is rural tourism, which is the focal point of this study, especially those initiatives for rural tourism in natural parks. Rural tourism is a development factor that will help to correct regional imbalances. Developmental politics related directly to wealth generation in these rural areas can be bolstered by this activity. This study will estimate a forecast to model monthly rural tourist demand in Andalusia for 2014. Its aim is to reveal its evolution in the immediate future in order to propose measures to encourage activity in said tourism sector, by making use of the 24 natural parks and protected areas located in this region.

\section{KEYWORDS}

\section{Rural Tourism; Rural Development; Natural parks; Andalusia; Demand Forecast}

\section{Introduction}

Rural tourism is a tool to further regional development where there is a socio-economic imbalance. In Spain, rural areas with low levels of income and productivity still prevail. Generally, they focus their production on economic activities directly related to the primary sector and suffer high rates of unemployment. They need to diversify their income.

These regions need sustainable growth through an economic culture based on the efficient administration of rural resources, involving the population whose main aim is to achieve a socio-economic and environmental bal- ance. According to Etxano [1], rural tourism will provide additional income to what they already receive and stable employment. All in all, it will contribute to reducing poverty and redistributing income. We do not propose making tourism the main source of income in these regions, but we feel it could be an additional income contribution for the inhabitant.

Mediano [2] and Buckley [3] point out that when tourists wish to enjoy the natural environment, they are inclined to opt for rural tourism in contact with that natural environment to get away from traditional sun and sea tourism, because the latter tourism no longer satisfies new inclinations that have been appearing in our society 
in recent years. What makes rural tourism a more popular emerging tourism is that the environment is a cause for concern in society, involving the search for sustainable development along with the need to seek satisfaction in one's free time, for example by being in contact with nature or staying with a family. It satisfies needs that the tourist feels nowadays to a greater degree, assert Devesa, Laguna \& Palacios [4]. A new market niche has made its appearance due to this change in values of current tourist consumers. Rural areas can take advantage of this niche to generate additional income.

\section{Rural Tourism: Economic Factor in Rural Areas}

Although our research deals with rural tourism, we are not going to delve too deeply into the complex current bibliography to define what rural tourism means and involves. Experts use different criteria to establish their definitions with clarity and accuracy which means that even today there is no unanimous one. In fact, we can find that the term has different meanings. The first one, by Traverso [5] says: "the tourist activity of sustainable establishment in the rural environment" and the second, by Blanco [6] says: "a singular expression of the new ways of tourism, characterized by: 1) being developed away from urban settlements generally; 2) using diverse natural or cultural resources characteristic of rural environment resources; 3) contributing to local development and to tourism diversification and competitiveness.

Consequently, as Lane [7] says, rural tourism in its purest form should be:

- Located in rural areas.

- Functionally rural-built upon the rural world's special features of small-scale enterprise, open space, contact with nature and the natural world, heritage, traditional societies and traditional practises.

- Rural in scale-both in terms of buildings and settlements - and, therefore, usually small-scale.

- Traditional in character, growing slowly and organically, and involved with local families. It will often be very largely controlled locally and developed for the long term good of the area.

- Of many different kinds, representing the complex pattern of rural environment, economy, history and location.

Starting from these premises, Sanagustín, Moseñe and Gómez [8] consider that rural tourism will help to make the rural area more dynamic and up-to-date, helping to solve arduous socio-economic problems that these regions have to face up to. Dependence on generated income in the primary sector is also one of those problems as seen in Figure 1.

Rural Andalusia has a large population working in the agricultural sector. Statistical studies show that in over
$50 \%$ of Andalusian towns, there are more than $25 \%$ of the population working in the primary sector, thus demonstrating an urgent need to diversify income. Rural tourism represents a key component in the socio-economic development in the region, making it possible to diversify the income of the rural population to guarantee prosperous development of the zone as it proposes an activity that will generate additional income and an element that distributes that income. Soteriades considers [9] indoor areas have to be taken into consideration to make the most of the opportunity that has emerged. They can fill a gap in the market because of the new interest in this type of tourism in recent decades with respect to sportive, cultural, and gastronomic activities in a rural environment.

Multiple factors have had a bearing on the change in tourist consumer's habits and values; it is essential to define the profile of this tourism consumer to offer a specialised product adapted to the needs of this tourism.

According to Millán \& Melian [10], rural tourism is an economic factor with some features that make it special. This tourism is carried out with more periodicity, decreasing the typical seasonal nature of these zones which is of great importance from an economic point of view, mainly because the employment created will not be temporary like most employment created by tourism. Tourism leads to a multiplying effect in the population of these rural areas. It diversifies the income obtained; it decreases dependence on the primary sector and reduces the economic risk which characterises it. Parada \& Rodriguez assert [11] that rural tourism will help to redistribute income between regions and will encourage the creation of employment directly.

At the same time, Ciruela notes [12] that the establishment of tourist activity in rural areas may be an element that depends on other areas. It is an exodus from urban areas on the part of the population. Equally, this tourism will help to decrease the high rates of unemployment. These two are the greatest difficulties facing these developing societies.

Fuller states [13]: it is not a question of making tourism the main income resource in these areas; on the contrary, it is a contribution of additional income for inhabitants because if the opposite took place, it would entail a high probability of saturation in the rural area. Miller et al. [14] proposes the promotion of a sustainable environment to generate wealth and employment in the course of time. So, maintenance and conservation of the environment will lead to a tourist development that is respectful of the natural and cultural environment.

What are equally essential are co-operation, dialogue and the co-ordination of socio-economic factors and institutions (local, regional and supranational). Furthermore, it is necessary to implicate society and to educate 


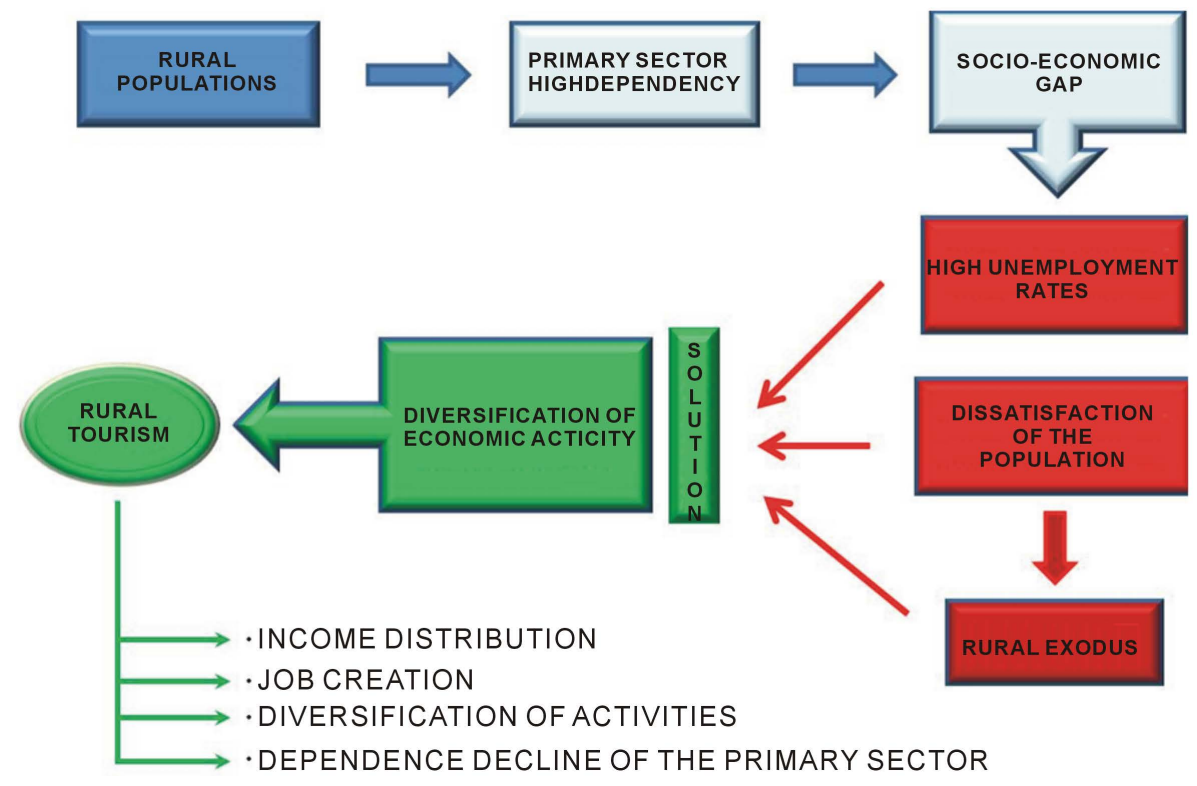

Figure 1. Rural tourism concept map.

it. Of course, the participation of the people is a momentous factor in raising the level of association between towns. And one of the main weaknesses is the increasing public awareness of this potential boon to be exploited in the region. It is necessary to raise the region's inhabitants' degree of commitment toward tourism matters, because they will be the most benefited. Equally, public bodies should promote development plans to make tourism activity easier in these zones. Although the growth of every region has to come from within the region itself, we should consider the resources and possibilities of the area to encourage them to offer a product which satisfies tourist consumers' needs fully.

Anton, Ne-lo \& Orellana [15] argue that tourist activity will not cancel out that of agriculture but will help to correct regional imbalances. Small growers and family farms will be able to benefit from the greater involvement of society in this sector. But, according to Buckey [16] and McAreavey \& McDonagh [17], rural tourism will also spark off negative effects in these areas; in the long-term, the cost of living will increase, agricultural area will decrease because of all these things; it will be necessary to have effective and efficient planning and management of all regional resources and be aware that tourist destinations should not run the risk of flooding, which would cause them to lose all their charm, affirm Zhong, Deng, Song and Ding [18].

\section{Rural Tourism in Andalusia}

\subsection{Introduction}

The regional autonomy of Andalusia exhibits a precarious economic situation with high unemployment rates
(36.37\%), 10 points over the Spanish average (28.98\%), along with low activity rates (58.94\% compared to the $59.94 \%$ national average for the third trimester of 2013). It is one of the communities most affected by the economic crisis, which is especially serious in the rural areas of the region.

Analyzing employment by sectors (Table 1), the Andalusian population comprises 2.53 million people, which represents $15 \%$ of those employed nationwide, By sectors, $6.1 \%$ of workers are dedicated to agriculture, which is 2 points higher than the Spanish average of 4.2, and $79.7 \%$ are in the service sector, especially highlighting those whose professional activity is dedicated to tourism (restaurants, hotels and shops).

On the other hand, the region has many important natural resources (24 natural parks and protected zones, Figure 2) and cultural heritage located in rural areas. In these natural spaces it is possible to develop an activity like tourism to help generate complementary economic income for those in the agricultural sector.

Since these natural resources can be used in a sutainable way, public administrations have lent their support to tourism as an opportunity to transform a rural productive structure, already obsolete as a result of the loss of interest in its facet as a supplier of primary products. In this sense, community initiative through the application of Leader structural funds (from the European Union), and the Spanish program PRODER (set of rural development programs that incorporate endogenous development initiatives that have been implemented exclusively in Spain) have shown to be efficient instruments, although it is true that, according to Pulido and Cardenas [20], there have been diverse results in different regions of Spain. 
Table 1. Employment in each economic sector (third trimester 2013).

\begin{tabular}{ccccc}
\hline Sectors & Andalusia (thousands of persons) & \% Total Andalusia & Spain (thousands of persons) & \% Total Spain \\
\hline Agriculture & 155.6 & 6.1 & 705.6 & 4.2 \\
Industry & 217.9 & 8.6 & 2280.2 & 13.5 \\
Construction & 139.3 & 5.5 & 1013.5 & 6.1 \\
Services & 2019.5 & 79.7 & 12823.8 & 76.2 \\
TOTAL & 2532.3 & 100 & 16823.1 & 100 \\
\hline
\end{tabular}

Data source: National Institute of Statistics [19].

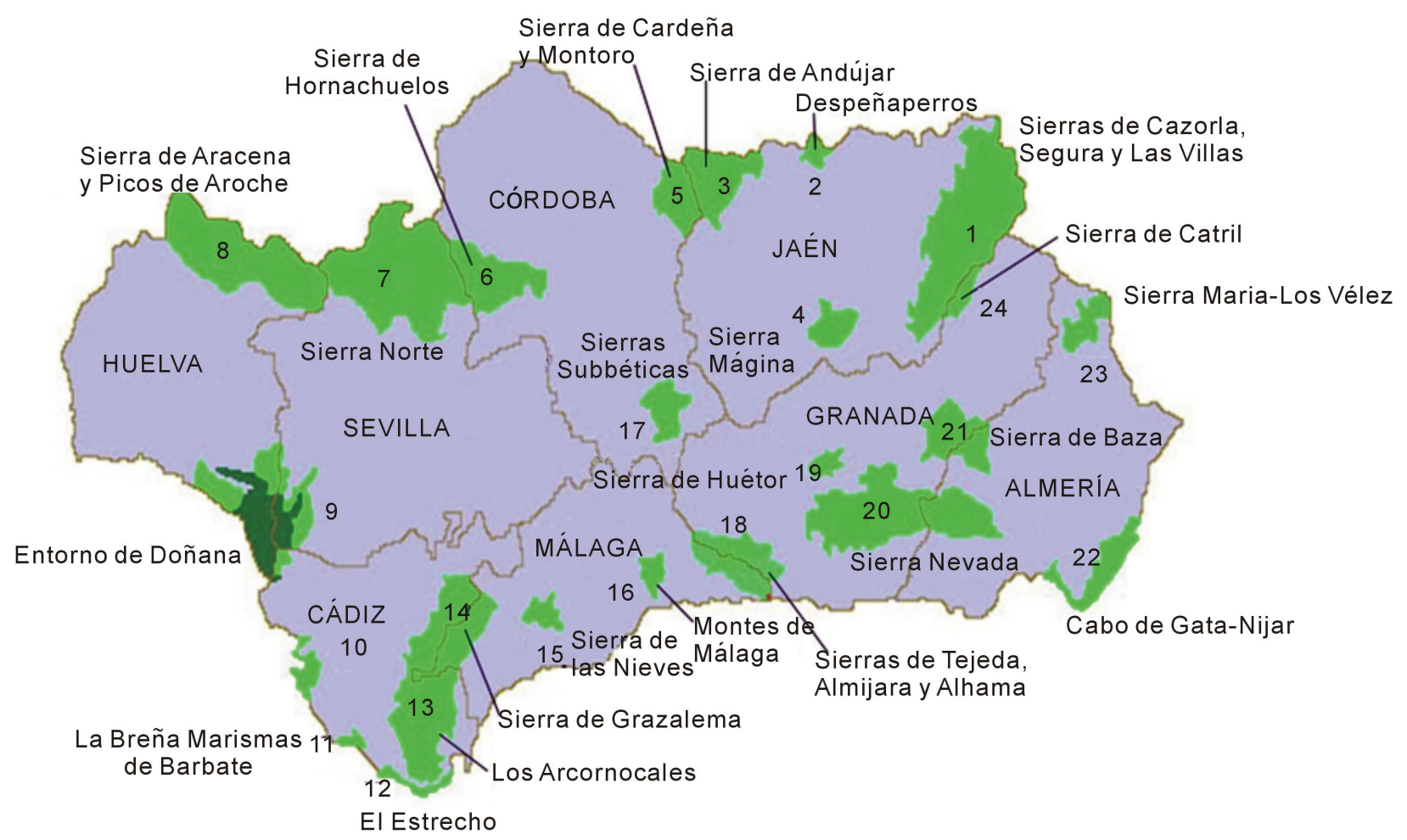

Figure 2. Natural Parks in Andalusia.

\subsection{Evolution of Rural Tourism}

In general, since the outbreak of the financial crisis, the Andalusian tourism sector has gone downhill, An example is the volume of employment created in this sector. In 2008 Andalusia held the first place in the ranking of regions $(16.4 \%$ of all jobs generated in the tourism sector at national level), falling to third position in 2010 (15.3\% of all jobs generated in the tourism sector at national level). This has entailed, among other consequences, the destruction of 33.500 jobs in the period in question. Rural Andalusian tourism, in particular, has also been negatively affected by the adverse economic situation. Figure 3 shows the evolution of rural tourism in the 8 Andalusian provinces in 2000-2010. Almost all the provinces have undergone a decrease in their number of rural tourists since 2009 as a consequence of the economic crisis, since most visitors come from the Andalusian community itself or other Spanish regions.

\section{Methodology}

\subsection{ARIMA Models}

A time series is defined as a set of data collected sequentially in time. It has the property that neighbouring values are correlated. This tendency is called autocorrelation. A time series is said to be stationary if it has a constant mean and variance. Moreover the autocorrelation is a function of the lag separating the correlated values and called the autocorrelation function (ACF).

A stationary time series $\left\{Y_{t}\right\}$ is said to follow an autoregressive moving average model of orders $\mathrm{p}$ and $\mathrm{q}$ (designated $\operatorname{ARMA}(p, q)$ ) if it satisfies the following difference equation:

$$
\begin{aligned}
& Y_{t}-\phi_{1} Y_{t-1}-\phi_{2} Y_{t-2}-\phi_{3} Y_{t-3}-\cdots-\phi_{p} Y_{t-p} \\
& =a_{t}-\theta_{1} a_{t-1}-\theta_{2} a_{t-2}-\theta_{3} a_{t-3}-\cdots-\theta_{q} a_{t-q}
\end{aligned}
$$

or: 


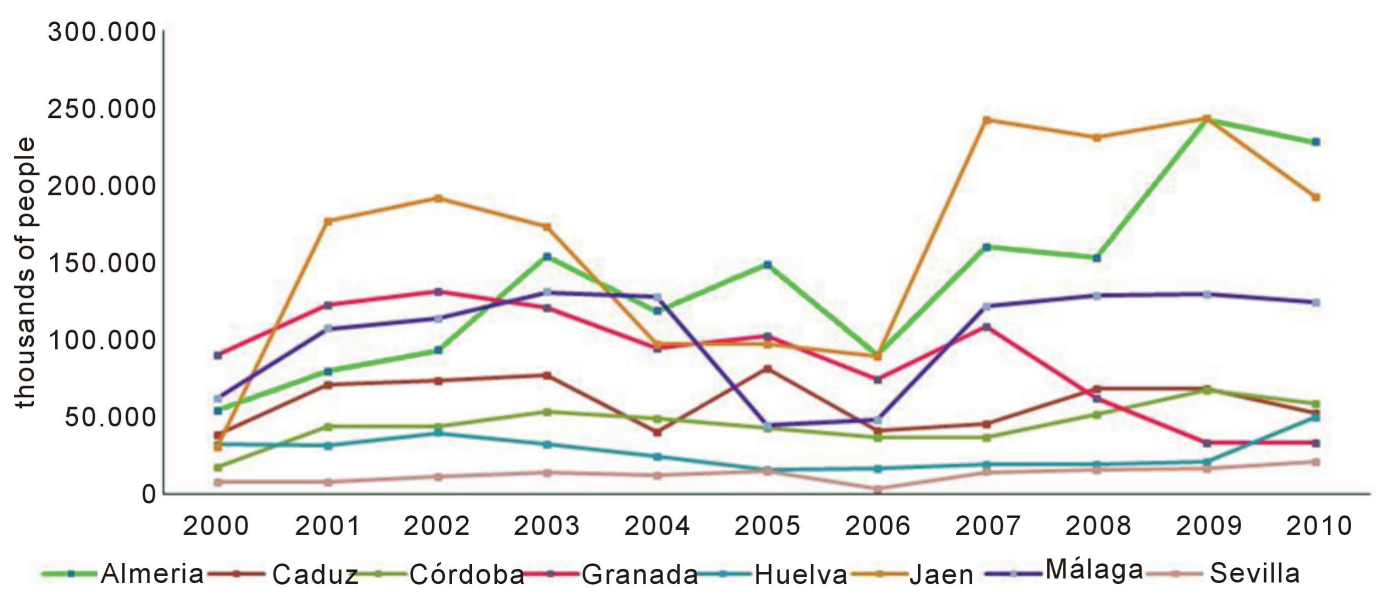

Figure 3. Evolution of rural tourism in Andalusian provinces 2000-2010.

$$
\phi(B) Y_{t}=\theta(B) a_{t}
$$

where $\left\{a_{t}\right\}$ is a sequence of uncorrelated random variables with zero mean and constant variance, called a white noise process, and the $\phi_{i}$ 's and $\theta_{j}$ 's constants;

$$
\begin{aligned}
& \phi(B)=1-\phi_{1} B^{1}-\phi_{2} B^{2}-\phi_{3} B^{3}-\cdots-\phi_{p} B^{p} \\
& \text { and } \theta(B)=1-\theta_{1} B^{1}-\theta_{2} B^{2}-\theta_{3} B^{3}-\cdots-\theta_{q} B^{q}
\end{aligned}
$$

and $B$ the backward shift operator defined by:

$$
B^{k} Y_{t}=Y_{t-k}
$$

If $p=0$, the model (1) becomes a moving average model of order q (designated MA(q)). If, however, $q=0$ it becomes an autoregressive process of order $p$ (designated $\operatorname{AR}(\mathrm{p})$ ). An $\operatorname{AR}(\mathrm{p})$ model may be defined as a model whereby a current value of the time series $Y_{t}$ depends on the immediate past $\mathrm{p}$ values: $Y_{t-1}, Y_{t-2}, Y_{t-3}, \cdots$ $Y_{t-\mathrm{p}}$. On the other hand an MA(q) model is such that the current value $X_{t}$ is a linear combination of immediate past values of the white noise process: $a_{t-1}, a_{t-2}, a_{t-3}, \cdots, a_{t-q}$. Apart from stationarity, invertibility is another important requirement for a time series. It refers to the property whereby the covariance structure of the series is unique. Moreover it allows for meaningful association of current events with past history of the series.

An AR(p) model may be more specifically written as:

$$
Y_{t}-\phi_{p_{1}} Y_{t-1}-\phi_{p_{2}} Y_{t-2}-\phi_{p_{3}} Y_{t-3}-\cdots-\phi_{p_{p}} Y_{t-p}=a_{t}
$$

Then the sequence of the last coefficients $\left\{\phi_{i i}\right\}$ is called the partial autocorrelation function (PACF) of $\left\{Y_{t}\right\}$.

The ACF of an MA(q) model cuts off after lag q whereas that of an AR(p) model is a combination of sinusoidals dying off slowly. On the other hand the PACF of an MA(q) model dies off slowly whereas that of an AR(p) model cuts off after lag p. AR and MA models are known to exhibit some duality relationships. These include:
1) A finite order $A R$ model is equivalent to an infinite order MA model.

2) A finite order MA model is equivalent to an infinite order AR model.

3) The ACF of an AR model exhibits the same behaviour as the PACF of an MA model.

4) The PACF of an AR model exhibits the same behaviour as the ACF of an MA model.

5) An AR model is always invertible but is stationary if $\phi(B)=0$ has zeros outside the unit circle.

6) An MA model is always stationary but is invertible if $\theta(B)=0$ has zeros outside the unit circle.

Parametric parsimony consideration in model building entails preference for the mixed ARMA fit to either the pure AR or the pure MA fit. Stationarity and invertibility conditions for model (1) or (2) are that the equations $\phi(B)=0$ and $\theta(B)=0$ should have roots outside the unit circle respectively.

Often, in practice, a time series is non-stationary. Box and Jenkins [21] proposed that differencing of appropriate order could render a non-stationary series $\left\{Y_{t}\right\}$ stationary. Let degree of differencing necessary for stationarity be $d$. Such a series $\left\{Y_{t}\right\}$ may be modeled as:

$$
\phi(B) \nabla^{d} Y_{t}=\theta(B) a_{t}
$$

where $\nabla^{d}=(1-B)^{d}$ and in which case $\phi(B) \nabla^{d}=0$ shall have unit roots $d$ times. Then differencing to degree $d$ renders the series stationary. The model (3) is said to be an autoregressive integrated moving average model of orders p, d and q and designated ARIMA(p, d, q).

\subsection{Seasonal ARIMA Models}

A time series is said to be seasonal of order $d$ if there exists a tendency for the series to exhibit periodic behaviour after every time interval $d$. Traditional time series methods involve the identification, unscrambling and estimation of the traditional components: secular trend, 
seasonal component, cyclical component and the irregular movement. For forecasting purpose, they are reintegrated. Such techniques could be quite misleading.

The time series $\left\{Y_{t}\right\}$ is said to follow a multiplicative $(\mathrm{p}, \mathrm{d}, \mathrm{q}) \times(\mathrm{P}, \mathrm{D}, \mathrm{Q})_{\mathrm{s}}$ seasonal ARIMA model if:

$$
\phi(B) \Phi\left(B^{s}\right) \nabla^{d} \nabla_{s}^{D} Y_{t}=\theta(B) \Theta\left(B^{s}\right) a_{t}
$$

where $\Phi$ and $\Theta$ are polynomials of order $P$ and $Q$ respectively. That is:

$$
\begin{gathered}
\Phi\left(B^{s}\right)=1-\Phi_{1} B^{1 s}-\Phi_{2} B^{2 s}-\cdots-\Phi_{P} B^{P s} \\
\Theta\left(B^{s}\right)=1-\Theta_{1} B^{1 s}-\Theta_{2} B^{2 s}-\cdots-\Theta_{Q} B^{Q s}
\end{gathered}
$$

where the $\Phi_{i}$ and the $\Theta_{j}$ are constants such that the zeros of the Equations (5) and (6) are all outside the unit circle for stationarity or invertibility respectively. Equation (5) represents the autoregressive operator whereas Equation (6) represents the moving average operator.

Existence of a seasonal nature is often evident from the time plot. Moreover for a seasonal series the ACF or correlogram exhibits a spike at the seasonal lag. Box and Jenkins [21] and Madsen [22] are a few authors that have written extensively on such models. A knowledge of the theoretical properties of the models provides basis for their identification and estimation, assert Harrison [23].

\section{The Demand for Rural Tourism in Andalusia}

\subsection{The Model of Demand}

The demand for rural tourism in Andalusia is a seasonal variable; the month of August receives the greatest influx of tourists in rural areas, coinciding with summer vacations (Figure 4). During this period, certain rural areas find themselves saturated with visitors and unable to adequately meet existing demand since there is too little hotel accommodation, and local businessmen are not interested in widening the offer since there is little occupancy the rest of the year, except for long weekends and holidays.

This section has tried to model the rural tourist variable in Andalusia, taking a sample that goes from January 2000 to December 2010 (132 data). To do so, the BoxJenkins methodology (BJ) is what is used, technically known as the ARIMA methodology. According to Gujarati [24], the virtuality of this forecasting method is not in the construction of uniequational models or simultaneous equations, but in the analysis of probabilistic or stochastic properties of the economic time series itself (in this case of the number of rural tourists in Andalusia), under the philosophy of "allowing the information to speak for itself”. Unlike regression models where the rural tourist variable can be explained by other regressors like consumer price index, income, etc., in the time series models

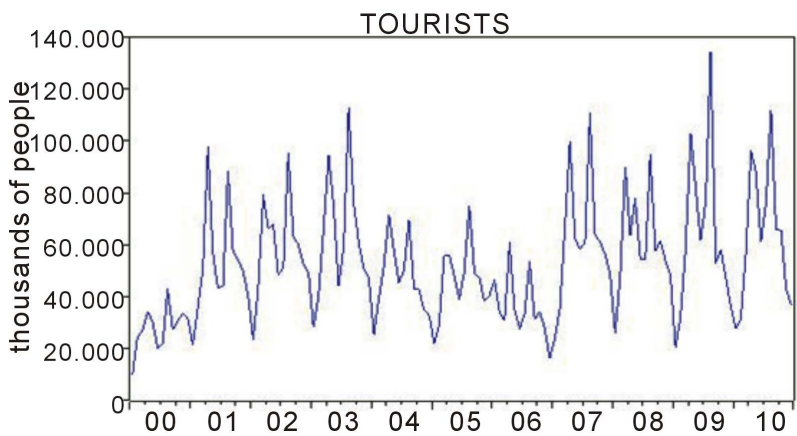

Figure 4. Evolution of rural tourism in Andalusia month by month (January 2000 to December 2010).

(BJ) the rural tourist variable can be explained by past or lagging values and by stochastic terms of error. The model used is a seasonal univariate ARIMA:

$$
\phi(B) \Phi\left(B^{s}\right)(1-B)^{d}\left(1-B^{s}\right){ }^{D} Y_{t}^{(\lambda)}=\theta(B) \Theta\left(B^{s}\right) a_{t}
$$

where the parameter $\lambda$ represents the correction of the tendency of variance of the series, and the nabla polynomials $\left((1-B)^{d}\left(1-B^{s}\right)^{D}\right)$ represent the correction of tendencies in average and cycle. The model obtained has been validated, both in its coefficients as well as in errors, through the Dickey-Fuller's unit root statistics and the ARCH test.

\subsection{Results: Estimating the Demand for Rural Tourism in Andalucia for 2014}

The demand for rural tourism in Andalusia, called tourism in the model, is a variable with variance tendency, which has been corrected with the Box-Cox transformation $\operatorname{Cox} \lambda=0.3$ (tourism^$\wedge 0.3$ ), and tendency in average and cycle that has been corrected with average and cyclical differentiation. The estimated model of monthly demand prediction for rural tourism in Andalusia is:

$$
\begin{aligned}
& \left(1+0.485303 B^{12}\right)(1-B)^{1}\left(1-B^{12}\right)^{1} \text { tourism }^{0.3} \\
& t_{\Phi_{1}=5.825^{*}} \\
& =(1+0.581937 B) a_{t} \\
& \quad t_{\theta_{1}=7.267^{*}}
\end{aligned}
$$

The Table 2 includes data of the ARCH test and the Dickey Fuller unit root test, which show that the model has no autocorrelation and is stationary.

This model has been used to make monthly predictions for the year 2014, which can be found in Table 3 and Figure 5. The deduction is that the evolution of tourism will follow similar tendencies to 2013, revealing accentuated seasonality in the month of August. With respect to the evolution of rural tourism figures, between 2010 and 2014 there is a decrease in the total volume of visi- 
Table 2. ARCH test and unit root test.

\begin{tabular}{ccccc}
\hline \multicolumn{5}{c}{ Heteroskedasticity Test: ARCH } \\
\hline F-statistic & 3.102654 & Prob.F(1.104) & 0.0811 \\
Obs ${ }^{*}$ R-squared & 3.070711 & Prob. Chi-Square(1) 0.0797 \\
\hline * Significant parameters $\alpha=0.05 ;$ \\
Absence of conditional autoregressive heteroskedasticity. \\
\hline \multicolumn{5}{c}{ Null: unit root (assumes individual unit root process) } \\
\hline Im, Pesaran and Shin W-stat & -12.1768 & 0.0000 & 1 & 117 \\
ADF - Fisher Chi-square & 76.3364 & 0.0000 & 1 & 117 \\
PP - Fisher Chi-square & 83.2745 & 0.0000 & 1 & 118 \\
\hline
\end{tabular}

Stationary series.

Table 3. Forecast for rural tourism demand in Andalusia for 2014 (thousands of persons).

\begin{tabular}{ccc}
\hline & Year 2010 & Year 2014 \\
\hline January & 27.722 & 26.952 \\
February & 31.091 & 30.128 \\
March & 56.603 & 54.248 \\
April & 96.199 & 98.125 \\
May & 88.145 & 85.369 \\
June & 61.214 & 62.402 \\
July & 76.193 & 76.095 \\
August & 111.884 & 112.324 \\
September & 65.991 & 64.247 \\
October & 65.431 & 66.789 \\
November & 42.949 & 44.658 \\
December & 36.670 & 35.789 \\
TOTAL & $\mathbf{7 6 0 . 0 9 2}$ & $\mathbf{7 5 7 . 1 2 6}$ \\
\hline
\end{tabular}

tors (from 760.092 to 757.126 ).

In order to alleviate this fall in tourism and the marked seasonality of visits, new markets are proposed. To do so, it would be necessary to promote the opportunities that these rural areas offer in international tourism fairs in order to attract foreign tourists. It must be kept in mind that currently $77 \%$ of those visiting these areas are Spanish (43\% from Andalusia and 34\% from the rest of Spain) (Figure 6).

Therefore, a solution at the current juncture of rural Andalusian tourism would be to attract tourists from other countries where the crisis has not been so serious or is already in phase of recuperation. Moreover, the offer has to be oriented toward those segments of the population with higher buying power, which would also lead to more overnight stays and higher average spending.

\section{Conclusions}

In conclusion, we will briefly sum up what has been discussed up to now. The first section sets out how a rural area has to develop into a tourist product. Thus, this sector can provide additional income sources for inhabitants of the region. Also, with the help of public and private bodies fomenting all potential attractions, the rural area can consolidate itself as a generator of a great part of regional economy and tourist destinations. These areas have to adopt measures to improve the image of the area, to promote a type of tourism where visitors can get involved and share in the every-day life of their destinations (daily tasks, customs, ways of local life...), simultaneously rescuing folk activities. All these will offer a degree of differentiation with respect to other rural destinations in the products and services offered by the area.

Although markets for rural tourist destinations are progressing at an incredible rate, in Andalusia we are still in time to be the first region in supply rural tourism. Therefore companies, not only hotels but all the complementary services (area stores, craftsmen...), should anticipate with swiftness and precision, taking into consideration the forecast for demand which can help them to invest appropriately in this wealth resource which is rural tourism. However it is also true that there has to be a change in tourism promotion policies in Andalusia, which have always been too oriented towards the beach and sun.

Rural Andalusian tourism has experienced a drop in the number of visitors, to a great extent, due to its mostly national tourism from Spanish regions that have been greatly affected by the financial crisis. In this sense, the origin of tourists must be diversified to include the whole international market.

Natural Parks are natural areas, little transformed by human exploitation or occupation that, due to its beautiful landscapes, the representativeness of ecosystems or the uniqueness of its flora, fauna or geomorphological formations, have ecological values, aesthetic, educational and scientific conservation deserve preferential treatment. There are 24 national parks and protected areas in Andalusia which can help to increase the number of visitors, and reverse this falling trend in demand in the forecast made by the ARIMA model. It is noteworthy that the special contribution to development and economic diversification of these natural spaces are given by the emergence of new tourist activities like saltworks tourism, birdwatching and agritourism. These activities are configured as future economic activities, with the potential to meet social, economic and environmental functions such as setting the population and conservation of natural and cultural heritage of these territories. They usually develop in slightly modified natural environments and present an offer of nature, adventure, culture and tradition. These tourism activities are managed by the local community, which can be integrated into environmental conservation activities or rural work and also have the potential to serve as an awareness tool for residents and visitors, and as a factor of local socio-economic diversification. 


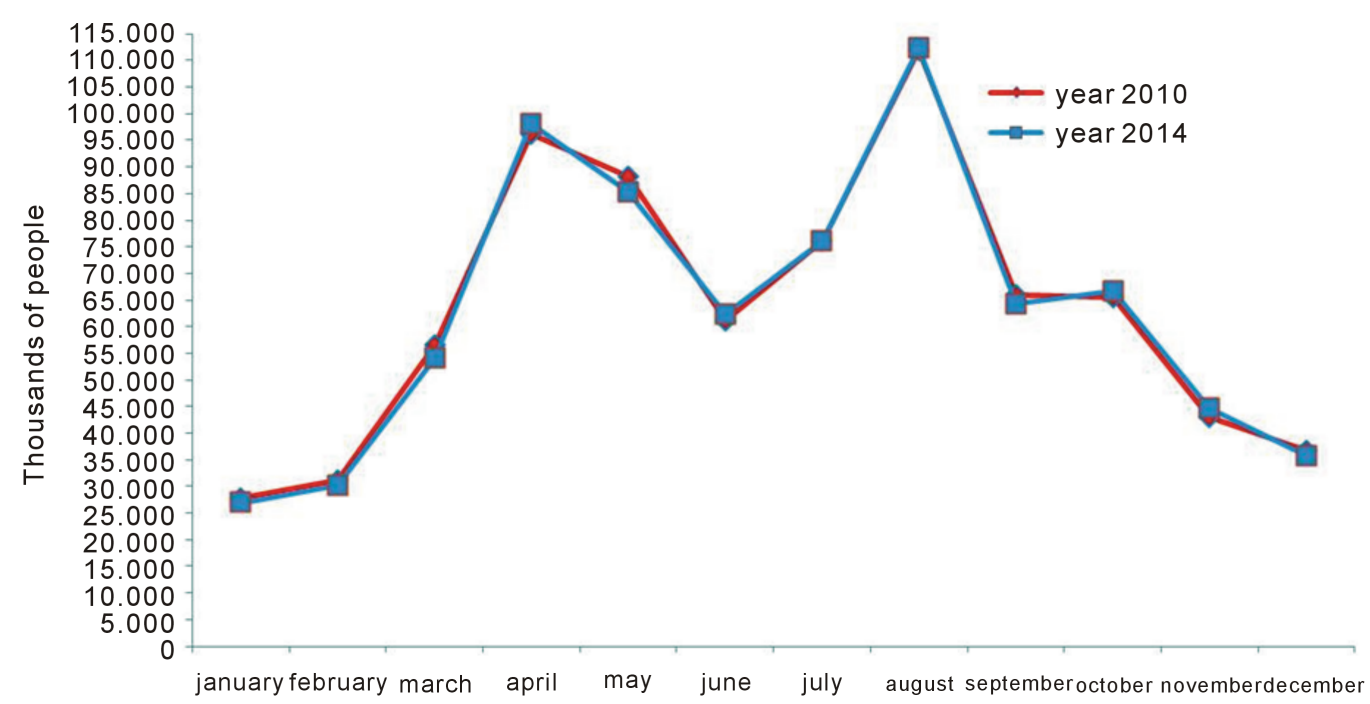

Figure 5. Monthly forecast for the number of rural tourists in Andalusia for 2014 and compared to 2010.
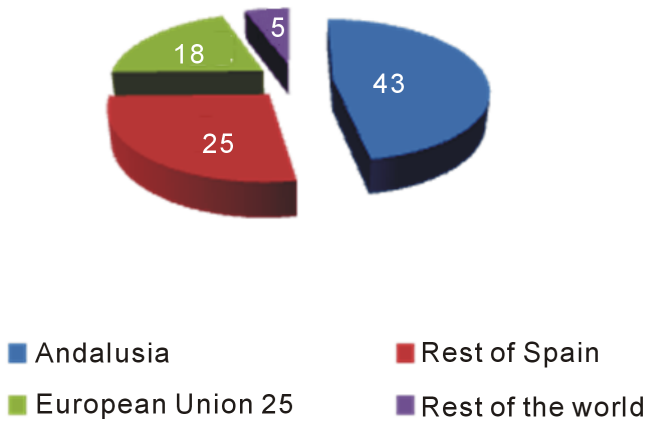

Figure 6. Place of origin of rural tourism visitors in Andalusia.

However, companies that are located in these natural areas have to face certain problems. They are usually small family businesses managed in a traditional way, and the staff training is low. These characteristics give them a great difficulty of innovation in products and processes, a low transfer of good practices and knowledge between them and a considerable lack of channels to reach their customers.

The solution for businesses located in these natural parks involves the assumption that innovation is not just developing new products, services, processes and technologies. Instead, what is important is innovation in models that allow the development of the brand "Natural Parks of Andalusia".

The design of a real tourism policy for these spaces should be the framework in which to insert any tourist activity that can generate economic expansion. Regional authorities and businesses in the sector should modify their current policy of tourism promotion in the region to stress the importance of interior tourism and create a framework for rural Andalusian tourism so that this region is no longer known exclusively for its sun and beach alternatives, but also as a region with a rural milieu that is an as-yet-hidden treasure.

Finally, the inhabitants of these rural Andalusion zones have a real need to increase and diversify their sources of income. To do so, rural tourism is an optimum option to help alleviate the long-suffering economy of the inhabitants in these areas.

\section{REFERENCES}

[1] I. Etxano, "Desarrollo rural en Espacios Naturales Protegidos: el caso del Parque Natural de Gorbeia (19942008),” Lurralde: Investigación y Espacio, Vol. 32, 2009, pp. 197-226.

[2] L. Mediano Serrano, "La Gestión de Marketing en el Turismo Rural,” Ediciones Pearson Prentice Hall, Madrid, 2004.

[3] R. C. Buckley, “Tourism and Environment,” Annual Review of Environment and Resources, Vol. 36. 2011, pp. 397-416. http://dx.doi.org/10.1146/annurev-environ-041210-13263 $\underline{7}$

[4] M. Devesa, M. Laguna and A. Palacios, "The Role of Motivation in Visitor Satisfaction: Empirical Evidence in Rural Tourism,” Tourism Management, Vol. 31, No. 4, 2010, pp. 547-552. http://dx.doi.org/10.1016/j.tourman.2009.06.006

[5] J. Traverso Cortés, "Comunicación Interpretativa: Variable Clave en el Marketing-Mix de las Empresas de Turismo Rural,” Estudios Turísticos, No. 130, 1996, pp. 3750.

[6] R. Blanco and J. Benayas, "El Turismo Como Motor del Desarrollo Rural. Análisis de los Proyectos Subvencionados por Leader I,” Revista de Estudios Agrosociales, No. 169, 1994, pp. 119-147.

[7] B. Lane, “What Is Rural Tourism?” Journal of Sustainable Tourism, Vol. 2, No. 1-2, 1994, pp. 7-21. 
http://dx.doi.org/10.1080/09669589409510680

[8] M. V. Sanagustín Fons, J. A. Moseñe Fierro and M. Gómez y Patiño, "Rural Tourism: A Sustainable Alternative,” Applied Energy, Vol. 88, No. 2, 2011, pp. 551-557. http://dx.doi.org/10.1016/j.apenergy.2010.08.031

[9] M. Soteriades, "Clusters et Reseaux Dans le Cadre du Tourisme Rural: L'experience Grecque,” Revista de la SEECI, No. 23, 2010, pp. 85-117.

[10] G. Millán and A. Melian, "El Turismo Rural en el sur de España: Análisis de la Oferta y Demanda,” CULTUR: Revista de Cultura e Turismo, No. 2, 2010, pp. 69-91.

[11] A. F. Parada and J. Rodríguez, "Economic Valuation of Parque Nacional El Gúacharo, Monagas state, Venezuela,” Revista Científica UDO Agrícola, Vol. 8, No. 1, 2008, pp. 88-97.

[12] A. M. Ciruela, "Diversificación de la Actividad Agraria Hacia el Turismo Rural: Un Modelo de Decisión Basado en Sociedades Cooperativas Agrarias Oleícolas," CIRIEC: España. Revista de Economía Pública, Social y Cooperativa, No. 61, 2008, pp. 205-232.

[13] N. Fuller, "Reflexiones Sobre el Turismo Rural Como via de Desarrollo: El Caso de la Comunidad de Antioquía, Perú,” Estudios y perspectivas en turismo, Vol. 20, No. 4, 2011, pp. 929-942.

[14] G. Miller, K. Rathouse, C. Scarles, K. Holmes and J. Tribe, "Public Understanding of Sustainable Tourism". Annals of Tourism Research, Vol. 37, No. 3, 2010, pp. 627-645. http://dx.doi.org/10.1016/j.annals.2009.12.002

[15] S. Antón, M. Nel-lo and A. Orellana, "Coastal Tourism in Natural Parks. An Analysis of Demand Profiles and Recreational Uses in Coastal Protected Natural Areas," Re- vista Turismo \& Desenvolvimento, Vol. 7-8, 2007, pp. 6981.

[16] R. Buckey, "Sustainable Tourism: Research and Reality”, Annals of Tourism Research, Vol. 39, No. 2, 2012, pp. 528-546. http://dx.doi.org/10.1016/j.annals.2012.02.003

[17] R. McAreavey and J. McDonagh, "Sustainable Rural Tourism: Lessons for Rural Development”, Sociologia Ruralis, Vol. 51, No. 2, 2011, pp. 175-194. http://dx.doi.org/10.1111/j.1467-9523.2010.00529.x

[18] L. Zhong, J. Deng, Z. Song and P. Ding, "Research on Environmental Impacts of Tourism in China: Progress and Prospect," Journal of Environmental Management, Vol. 92, No. 11, 2011, pp. 2972-2983. http://dx.doi.org/10.1016/j.jenvman.2011.07.011

[19] Instituto Nacional de Estadística, “Anuario Estadístico de España 2013,” INE, Madrid, 2013.

[20] J. I. Pulido and P. J. Cárdenas, "El Turismo Rural en España: Orientaciones Estratégicas Para una Tipología aún en Desarrollo,” Boletín de la Asociación de Geógrafos Españoles, No. 56, 2011, pp. 155-176.

[21] G. E. P. Box and G. M. Jenkins, “Time Series Analysis, Forecasting and Control,” Holden-Day, San Francisco, 1976.

[22] H. Madsen, “Time Series Analysis,” Chapman \& Hall/ CRC, London, 2008.

[23] E. Harrison, "A Multiplicative Seasonal Box-Jenkins Model to Nigerian Stock Prices," Interdisciplinary Journal of Research in Business, Vol. 2, No. 4, 2012, pp. 1-7.

[24] D. N. Gujarati, “Econometría,” McGraw Hill, México, 2003. 